\title{
EVALUATION OF PORT EFFICIENCY IN SHANGHAI PORT AND BUSAN PORT BASED ON THREE-STAGE DEA MODEL WITH ENVIRONMENTAL CONCERNS
}

\author{
Xiaoling $\mathrm{HUANG}^{*}$, Yawei $\mathrm{WANG}^{2}$, Xiamei DAI ${ }^{3}$, Jack Xunjie $\mathrm{LUO}^{4}$, Jihong $\mathrm{CHEN}^{5}$ \\ 1,2,3Transportation Engineering College, Dalian Maritime University, Dalian, China \\ ${ }^{4}$ Project Command Department, Shanghai International Port Group Ltd., Shanghai, China \\ ${ }^{5}$ College of Transport and Communications, Shanghai Maritime University, Shanghai, China
}

Received 13 January 2019; revised 3 April 2019, 28 May 2019; accepted 22 September 2019; first published online 20 November 2019

\begin{abstract}
The global green development has led many ports to impose measures to reduce emissions and improve port efficiency. As large-scale construction can do damage to the environment, it is not supported under the green strategy, which makes it more important to make full use of existing resources in the port competition. While, whether there is a relationship between emissions and port efficiency, and whether the relationship can reflect the problems in port management are vital factors need to be considered when making port development strategy. To solve the two problems, this paper takes the case of Shanghai Port and Busan Port, and uses the three-stage Data Envelopment Analysis (DEA) to evaluate the efficiency of the two ports respectively. Pollutant emissions from the ports are selected as an environmental variable in the second stage to examine their effects on the redundancy of input variables. The results indicate that the efficiency of Shanghai Port is insufficient due to excessive scale and pollutant emissions. Based on the results, some suggestions are given to improve the drawbacks. Furthermore, the use of the three-stage DEA to study the annual change in performance of a single target in this paper is also a novelty.
\end{abstract}

Keywords: port efficiency, pollutant emissions, three-stage DEA, Shanghai Port, Busan Port, cooperation.

\section{Notations}

\section{Abbreviations:}

BCC - one of the traditional DEA models, BCC model is under Variable Returns to Scale (VRS), and it is named by three operational research experts, R. D. Banker, A. Charnes and W. W. Cooper;

CCR - one of the traditional DEA models, CCR model is under Constant Returns to Scale (CRS), and it is named by three operational research experts, A. Charnes, W. W. Cooper and E. Rhodes;

CRS - Constant Returns to Scale;

DEA - Data Envelopment Analysis;

DMU - Decision-Making Unit;

ECAs - Emission Control Areas;

GDP - Gross Domestic Product;

SBM - Slacks-Based Measure;

SFA - Stochastic Frontier Analysis;

VRS - Variable Returns to Scale; crste - CRS technological efficiency, that is, comprehensive efficiency;

$d r s$ - decreasing returns to scale;

irs - increasing returns to scale;

scale - scale efficiency;

vrste - VRS technological efficiency, that is, pure technical efficiency.

Variables and functions:

$n$ - the number of DMU;

$m$ - the number of input indicators of each DMU;

$s$ - the number of output indicators of each DMU;

$\theta$ - pure technical efficiency, its value is between 0 and 1 , and the closer it is to 1 , the higher the pure technical efficiency of the DMU;

$\lambda_{j}$ - the weight coefficient of importance of DMU $j$;

$x_{i j}$ - the $i$-th input of the $j$-th DMU;

$y_{r k}$ - the $r$-th output of the $k$-th DMU;

*Corresponding author. E-mail: huangxiaoling@dlmu.edu.cn 
$S_{i l}$ - the slack variable of the $i$-th input of the $l$-th DMU, it is the difference between the actual value of the input and the target value under optimized efficiency;

$f^{l}$ - impact of external operating environment on slack variables of input indicators;

$Z_{i}$ - the collection of external operating environment indicators that have an impact on input indicators;

$\beta_{l}$ - the estimated parameter of the external operating environment;

$v_{i l}$ - statistical random error term, obeying $N\left(0, \sigma_{n}^{2}\right)$;

$u_{i l}$ - residual term of efficiency, obeying the non-negative unilateral normal distribution $N\left(\mu, \sigma_{n}^{2}\right)$.

\section{Introduction}

With the acceleration of globalization and the development of China's economic and trade (Chen, Yahalom 2013), the global economy center and shipping center are moving to Northeast Asia. Therefore, the competition for hub port among Northeast Asian ports is becoming increasingly strong. Undoubtedly, the competition between Shanghai Port and Busan Port, the two major international shipping centers having overlapping hinterlands, is getting fiercer. Competition exists in a variety of ways, such as port services, marketing strategies and more. Among them, port efficiency is a key factor in port competition. It refers to the extent to which ports use their resources effectively. Furthermore, with the process of global greening, large-scale development and construction are discouraged, which makes the port efficiency even more crucial.

Port efficiency is an important index to evaluate port development, and it is often calculated by DEA (Merkel, Holmgren 2017; Chen, Lam 2018; Wiegmans, Witte 2017). DEA is a non-parametric method wildly used to evaluate the relative effectiveness of the same departments (Markovits-Somogyi, Bokor 2014). The usage of DEA can be divided into two categories. One is to compare the efficiency of multiple objects at the same point of time, and the other is to evaluate the efficiency change of a single object during a continuous time period. For the first usage, Schøyen et al. (2018) measured efficiency of ports located in six countries, and adopted a second-stage regression analysis to examine sensitivities to the inclusion of country-specific measurements on logistics service delivery performance outcomes on port efficiency. Chang et al. (2018) used twostage approaches to examine whether ECAs regulations impact the efficiency of ports operating in the European Union and North America. They firstly used SBM-DEA model to evaluate the efficiency scores regarding berth length, number of container cranes and terminal total area as input variables, with cargo throughput as an output variable. Based on the efficiency scores, the second stage regression regarded city GDP, economic crisis and emission control as variables to examine their influence on port efficiency. Based on the emission inventory statistics of Shanghai Yangshan Port, Song (2014) concluded that social costs of port development include impacts on human health, environment and climate. He evaluated eco-efficiency of the port according to ship emissions and basic operation of port, and the results indicated that port efficiency is closely related to social and economic issues.

For the second usage, Lai et al. (2012) used CCR model to evaluate the allocation efficiency of health resources in Shanxi Province from 2000 to 2009. Yang and Guo (2015) used BCC model to evaluate the allocation efficiency of health resources in Beijing from 2004 to 2013. Zhou and Jiang (2010) evaluated the allocation efficiency of health resource from 2004 to 2007 based on CCR and BCC model taking four consecutive years as four DMUs. Through this usage, the evolution process of the efficiency change of the measured object can be seen intuitively, which is important when determining the development strategy of the object. While these three papers neglect the influence of external environmental variables on annual efficiency.

As can be seen above, environmental concerns have been brought into studies in port efficiency and ports are currently facing increasing demands to address environmental issues and achieve sustainable development goals (Cheon et al. 2017; Sun et al. 2017). For the handling of undesirable output, most literatures regard it as an output variable and the resulting efficiency is called environmental efficiency (Luo et al. 2014; Lee et al. 2014; Dobos, Vörösmarty 2019). However, this method can not evaluate the effect of undesirable output on redundancy of input variables. It just ranks the so-called environmental efficiency of multiple objects at the same point of time, and can not show the evolution process of the individual efficiency. The problems in port management can also not be founded out from the results of the environmental efficiency, so it is difficult to propose targeted solutions.

Therefore, the aims of this paper are to evaluate the port efficiency of Shanghai Port and Busan Port respectively, and examine the relationship between their emissions and port efficiency. By comparing the results of the two ports, the shortcomings in efficiency of Shanghai Port can be concluded, and then targeted suggestions for improvement will be put forward. As a result, this paper will use the three-stage DEA to evaluate the efficiency of two ports respectively for two reasons: eliminating the interference of external environmental factors; examining the effect of undesirable output on redundancy of input variables. The rest of this paper is organized as follows: Chapter 1 introduces the model of the three-stage DEA; Chapter 2 evaluates the efficiency of Shanghai Port and Busan Port respectively; Chapter 3 illustrates the influence of ports on environment; Chapter 4 gives proposals on improvement for Shanghai Port based on the results of Chapter 2; the final part makes conclusions.

\section{The three-stage DEA method}

DEA is a non-parametric technical efficiency analysis method based on relative comparison between evaluated objects. It was proposed by Charnes et al. (1978). The results of traditional DEA are affected by external environmental factors and random factors. Therefore, this paper adopts the three-stage DEA. 


\subsection{The first stage: DEA-BCC model}

DEA models can be divided into CCR model and BCC model. The former refers to CRS and the latter refers to VRS. The assumption of CRS is applicable only when all production units are producing under the optimal production scale. However, under the realistic conditions, due to factors such as imperfect competition and capital constraints, it is difficult to achieve optimal production scale. Therefore, this paper adopts BCC model.

In addition, DEA models can be divided into inputoriented, output-oriented and non-oriented models according to the way of measuring the efficiency. The inputoriented model measures the degree of inefficiency of the evaluated DMU from the perspective of input, focusing on the extent to which the inputs should be reduced for achieving technological efficiency without reducing the output. At present, faced with the fierce competition, many ports blindly increase investment for infrastructure, which causes excess facilities and serious waste of resources. Therefore, this paper adopts the input-oriented BCC model shown as follows.

Assuming there are $n$ DMUs, each DMU has $m$ kinds of inputs, $s$ kinds of outputs, then the efficiency of a DMU can be obtained by the following model (Banker et al. 1984):

$\min \theta$

subject to:

$$
\begin{aligned}
& \sum_{j=1}^{n} \lambda_{j} \cdot x_{i j} \leq \theta \cdot x_{i k}, i=1,2, \ldots, m ; \\
& \sum_{j=1}^{n} \lambda_{j} \cdot y_{r j} \geq y_{r k}, r=1,2, \ldots, s ; \\
& \sum_{j=1}^{n} \lambda_{j}=1 ; \\
& \lambda_{j} \geq 0, j=1,2, \ldots, n .
\end{aligned}
$$

Technical efficiency refers to the extent to which the production process of a production unit reaches the level of the industry. It reflects the technological level of the DMU. Since the BCC model is based on VRS, the technical efficiency obtained excludes the influence of scale. As a result, the technical efficiency obtained is called pure technical efficiency.

\subsection{The second stage: SFA model}

The efficiency values obtained in the first stage are affected by management inefficiencies, environmental factors, and random factors. The second stage takes the slack variables of each input indicator as dependent variables and the external environmental variables as independent variables. The stochastic frontier model is used for regression analysis. The principle is to adjust all the DMUs to the same environmental conditions while considering the influence of stochastic error. The regression model is shown as follows (Meeusen, Van den Broeck 1977; Aigner et al. 1977):

$$
S_{i, l}=f^{l}\left(Z_{i}, \beta_{l}\right)+v_{i l}+u_{i l} \text {. }
$$

\subsection{The third stage: DEA-BCC model}

Take the adjusted input values and the original output values into the BCC model to obtain the final efficiency values. Because the second stage effectively eliminates the influence of non-operational factors on efficiency, the DMUs are under the same environment. In addition, the efficiency obtained in the third stage is pure management efficiency, which accurately reflects the level of management. Only in this way can pertinent suggestions for management be put forward according to the efficiency results.

\section{Empirical analysis of the model}

\subsection{The first stage}

The input variables of port generally selected in relevant literature mainly include labour, berth length, berth number, etc. In addition, the output indicators mainly include cargo throughput, container throughput, customer satisfaction, etc. Considering the availability and accuracy of the data, this paper chooses the number of production berths, the length of production quay and the number of container cranes as input variables, while bulk cargo throughput and container throughput as output variables. The reasons are that the length of the production quay determines the productivity of the terminal, the number of production berths determines the waiting time of the ships outside the port and the number of container cranes determines the time that the ships stay on the berths. While the output of a port is mainly throughput including bulk cargo throughput and container throughput. Because the two are separately counted, there are two output variables.

Each year from 2005 to 2016 is selected as a DMU $\left(D M U_{S_{i}}\right.$ and $D M U_{F_{i}}$, where $S$ represents Shanghai Port and $F$ represents Busan Port, $i=2005,2006, \ldots, 2016$ ). In addition, the efficiency analysis of Shanghai Port and Busan Port is done respectively. The results calculated by DEAP 2.1 (Data Envelopment Analysis (Computer) Program) are shown in Table 1.

Shanghai Port achieved efficient in technique and scale in 2005, 2013, 2014 and 2016. From 2006 to 2012, Shanghai Port had been in the stage of increasing returns to scale, indicating that expanding the scale of the port could improve efficiency. However, after 2012, it was in the stage of constant returns to scale, indicating that the scale of the port was large enough and there was no need to expand it. In 2015, it was in the decreasing stage, indicating that the scale of the port was too large, and downsizing it could improve efficiency. This shows that in recent years, in order to attract more goods and expand market share, many ports, not only Shanghai Port, have been blindly increasing investment on infrastructure. In fact, too large a scale 
Table 1. Results of the first stage

\begin{tabular}{|c|c|c|c|c|c|}
\hline Port & Year & crste & vrste & scale & Returns to scale \\
\hline \multirow{13}{*}{ S } & 2005 & 1 & 1 & 1 & - \\
\hline & 2006 & 0.929 & 0.994 & 0.934 & irs \\
\hline & 2007 & 0.983 & 0.991 & 0.992 & irs \\
\hline & 2008 & 0.895 & 0.977 & 0.917 & irs \\
\hline & 2009 & 0.842 & 0.983 & 0.857 & irs \\
\hline & 2010 & 0.958 & 1 & 0.958 & irs \\
\hline & 2011 & 0.975 & 0.998 & 0.977 & irs \\
\hline & 2012 & 0.965 & 0.986 & 0.979 & irs \\
\hline & 2013 & 1 & 1 & 1 & - \\
\hline & 2014 & 1 & 1 & 1 & - \\
\hline & 2015 & 0.995 & 0.999 & 0.996 & $d r s$ \\
\hline & 2016 & 1 & 1 & 1 & - \\
\hline & mean & 0.962 & 0.994 & 0.967 & - \\
\hline \multirow{13}{*}{ B } & 2005 & 1 & 1 & 1 & - \\
\hline & 2006 & 0.963 & 0.992 & 0.971 & irs \\
\hline & 2007 & 1 & 1 & 1 & - \\
\hline & 2008 & 0.954 & 0.964 & 0.989 & irs \\
\hline & 2009 & 0.795 & 0.881 & 0.903 & irs \\
\hline & 2010 & 0.93 & 0.955 & 0.974 & irs \\
\hline & 2011 & 0.971 & 0.988 & 0.983 & irs \\
\hline & 2012 & 0.972 & 0.982 & 0.99 & irs \\
\hline & 2013 & 0.982 & 0.988 & 0.993 & irs \\
\hline & 2014 & 1 & 1 & 1 & - \\
\hline & 2015 & 1 & 1 & 1 & - \\
\hline & 2016 & 1 & 1 & 1 & - \\
\hline & mean & 0.964 & 0.979 & 0.984 & - \\
\hline
\end{tabular}

Notes: S - Shanghai Port; B - Busan Port. of a port has not only failed to improve efficiency, but also caused waste of resources, environmental pollution and ecological damage. In addition, the scale efficiency of Shanghai Port is generally lower than the pure technical efficiency, indicating that the scale is the main reason for the low efficiency of Shanghai Port.

In 2005, 2007, 2014, 2015 and 2016, Busan Port achieved efficient in technique and scale. From 2005 to 2013, the returns to scale of Busan Port had been mostly in an increasing state, indicating that increasing investment on infrastructure and expanding the scale of the port could improve efficiency. Since 2014, Busan Port has been in the stage of constant returns to scale, indicating that the scale of the port is large enough, the infrastructure is sufficient, and there is no need to expand capacity. While Busan Port is still developing its new port, which will also make the port oversized. Moreover, the pure technical efficiency of Busan Port is generally lower than the scale efficiency, indicating that the technical problem is the main reason for the low efficiency of Busan Port.

The target values of the evaluation indicators of nonefficient DMUs are shown in Table 2, where " $\mathrm{T}$ " represents target value and " $D$ " represents the difference between target value and actual indicator value. The value of the difference is obtained by the formula "difference = target value - actual indicator value". If the value is positive, it means that the corresponding indicator value is too small and should be increased. If it is negative, it indicates the indicator value is excessive and should be reduced. From the target values of input and output, under the existing input conditions, the actual corresponding output is insufficient. Alternatively, from the opposite perspective, under

Table 2. Target values of the evaluation indicators of non-efficient DMUs

\begin{tabular}{|c|c|c|c|c|c|c|c|c|c|c|c|}
\hline \multirow{3}{*}{ Port } & \multirow{3}{*}{ Year } & \multicolumn{6}{|c|}{ Input indicators } & \multicolumn{4}{|c|}{ Output indicators } \\
\hline & & \multicolumn{2}{|c|}{$\begin{array}{c}\text { Number of container } \\
\text { crane }\end{array}$} & \multicolumn{2}{|c|}{$\begin{array}{c}\text { Number of } \\
\text { production berths }\end{array}$} & \multicolumn{2}{|c|}{$\begin{array}{c}\text { Length of production } \\
\text { quay }\end{array}$} & \multicolumn{2}{|c|}{$\begin{array}{l}\text { Container } \\
\text { throughput }\end{array}$} & \multicolumn{2}{|c|}{$\begin{array}{c}\text { Cargo } \\
\text { throughput }\end{array}$} \\
\hline & & $\mathrm{T}$ & $\mathrm{D}$ & $\mathrm{T}$ & $\mathrm{D}$ & $\mathrm{T}$ & $\mathrm{D}$ & $\mathrm{T}$ & $\mathrm{D}$ & $\mathrm{T}$ & $\mathrm{D}$ \\
\hline \multirow{8}{*}{$S$} & 2006 & 98 & -7 & 620 & -17 & 58977.1 & -334.9 & 2171 & 0 & 579.4 & 41.9 \\
\hline & 2007 & 117 & -1 & 612 & -29 & 63323.8 & -1073.3 & 2615.2 & 0 & 614.7 & 53.2 \\
\hline & 2008 & 128 & -11 & 607 & -15 & 65817.1 & -1571.9 & 2870 & 72 & 634.9 & 53.2 \\
\hline & 2009 & 137 & -2 & 603 & -11 & 69074.3 & -1212.7 & 3017.6 & 517.4 & 651 & 59 \\
\hline & 2010 & 139 & 0 & 602 & 0 & 72537 & 0 & 2906.9 & 0 & 653.4 & 0 \\
\hline & 2011 & 154 & 0 & 605 & -1 & 72380.8 & -361.2 & 3320.0 & 146.1 & 727.6 & 0 \\
\hline & 2012 & 157 & -2 & 604 & -8 & 73143.5 & -1315.5 & 3387.7 & 134.8 & 735.6 & 0 \\
\hline & 2015 & 163 & 0 & 597 & -12 & 74332 & -829 & 3654 & 0 & 717.4 & 0 \\
\hline \multirow{7}{*}{ B } & 2006 & 78 & -10 & 300 & -12 & 34418 & -280 & 1230.3 & 27.3 & 178.5 & 0 \\
\hline & 2008 & 101 & -19 & 335 & -12 & 37092 & -1372.7 & 1342.5 & 0 & 198.8 & 12.3 \\
\hline & 2009 & 73 & -47 & 298 & -41 & 33588 & -7797.9 & 1196.1 & 0.6 & 169.9 & 0 \\
\hline & 2010 & 108 & -12 & 307 & -15 & 39831 & -3620.8 & 1415.7 & 0 & 226.3 & 26 \\
\hline & 2011 & 143 & -7 & 320 & -6 & 44744 & -539.5 & 1637.6 & 22.6 & 281.5 & 0 \\
\hline & 2012 & 154 & -23 & 323 & -14 & 46468 & -830.2 & 1705.7 & 1.1 & 298.7 & 0 \\
\hline & 2013 & 167 & -25 & 327 & -14 & 47999 & -574 & 1768.6 & 0 & 313.3 & 0 \\
\hline
\end{tabular}

Notes: S - Shanghai Port; B - Busan Port; T - target value; D - difference between target value and actual indicator value. 
the existing output level, the input indicators of the two ports have been redundant from 2005 to 2016, and the production potential has not been fully utilized.

\subsection{The second stage}

Considering the policy environment and regional economic development of a port may vary greatly every year, GDP per head and regional total export-import volume, which can reflect the policy environment and regional economic development are chosen as environmental variables. By choosing these two factors as environmental variables, the port efficiency for many years can be placed in basically the same external environment. In addition, considering the impact of natural environment on port efficiency, the $\mathrm{NO}_{\mathrm{x}}$ emission is selected as the environmental variable for the first time. $\mathrm{NO}_{\mathrm{x}}$ is one of the major pollutants produced by port production, and its environmental pollution has become a serious global problem. Environmental pollution leads to an increase in the cost of treating environment pollution of the port and also affects workers' health badly, which will influence the port efficiency. Therefore, this paper selects $\mathrm{NO}_{\mathrm{x}}$ emission as an environment variable to eliminate the impact of environmental pollution on port efficiency. Do the regression analysis by taking relevant data into FRONTIER 4.1 (Software for Stochastic Frontier Analysis), and the results are shown in Table 3.

If the estimated coefficient is negative, it means that the environmental variable can reduce the redundancy of the input variable, which is a good external environment variable. On the contrary, if the estimated coefficient is positive, it means that the environmental variable is a bad one. As can be seen from Table 3, $\mathrm{NO}_{\mathrm{x}}$ emission of Shanghai Port is a good external environment variable for the number of container cranes, which can reduce the amount of redundancy. While it is a bad environment variable for the number of production berths and the length of production quay. $\mathrm{NO}_{\mathrm{x}}$ emission of production berths and production quay is produced by vessels. Therefore, it can be understood that $\mathrm{NO}_{\mathrm{x}}$ emission from container cranes is in line with the requirements of sustainable development, while $\mathrm{NO}_{\mathrm{x}}$ emission from vessels is not in line with the requirements of sustainable development. As a result, Shanghai Port should strengthen the regulation on emission from berthing vessels. As for Busan Port, $\mathrm{NO}_{\mathrm{x}}$ emission is a good environment variable for the number of container cranes, the number of production berths and the length of production quay, indicating that the management of equipment emission and vessel emission in Busan Port is in place.

\subsection{The third stage}

Take the adjusted input values and the original output values into the BCC model, and the final efficiency values of the two ports are calculated by DEAP 2.1. The results are shown in Table 4. Comparing Table 1 and Table 4, it can be seen that there are 4 effective DMUs in the first stage of Shanghai Port, and 5 in the third stage. In addition, the averages of overall efficiency, pure technical efficiency, and scale efficiency of the third stage are improved compared with the first stage, indicating that the removal of redundant resources can fully exploit the production potential of each input indicator and improve efficiency. While there are 5 effective DMUs in the first stage of Busan Port, only 2 in the third stage. In addition, the average efficiency is reduced compared with the first stage, means that the technical problem rather than the scale is the reason for the inefficiency of Busan Port, which is also consistent with the results of the first stage.

As can be seen above, expanding the scale may not improve port efficiency. On the contrary, it may result in inefficiency of ports. In addition, emissions do affect the port efficiency, and the relationship between emissions and port efficiency can reflect the problems in port management. Furthermore, excessive scale and pollutant emissions also bring serious environmental problems, as illustrated in the next chapter.

Table 3. Results of the second stage

\begin{tabular}{|c|l|c|c|c|}
\hline Port & \multicolumn{1}{|c|}{ Indicators } & $\begin{array}{c}\text { Slack variables of the number } \\
\text { of container cranes }\end{array}$ & $\begin{array}{c}\text { Slack variables of the number } \\
\text { of production berths }\end{array}$ & $\begin{array}{c}\text { Slack variables of the length } \\
\text { of production quay }\end{array}$ \\
\hline \multirow{5}{*}{$S$} & Coefficient & 4.16 & -11.2 & $-1.34 \cdot 10^{3}$ \\
\cline { 2 - 5 } & NO $_{\mathrm{x}}$ emission & $-2.83 \cdot 10^{-4}$ & $1.57 \cdot 10^{-3}$ & $2.00 \cdot 10^{-1}$ \\
\cline { 2 - 5 } & GDP per head & $-1.03 \cdot 10^{-4}$ & $1.20 \cdot 10^{-4}$ & $1.63 \cdot 10^{-2}$ \\
\cline { 2 - 5 } & Total export-import volume & $3.16 \cdot 10^{-5}$ & $-1.19 \cdot 10^{-4}$ & $-1.56 \cdot 10^{-2}$ \\
\cline { 2 - 5 } & Sigma-squared & 25.3 & $1.43 \cdot 10^{2}$ & $6.42 \cdot 10^{5}$ \\
\cline { 2 - 5 } & Gamma & 1.00 & 1.00 & 1.00 \\
\hline \multirow{5}{*}{$\mathrm{B}$} & Coefficient & 2.39 & 5.00 & $-1.40 \cdot 10^{3}$ \\
\cline { 2 - 5 } & NO emission & $-3.370 \cdot 10^{-3}$ & $-4.84 \cdot 10^{-3}$ & $-9.59 \cdot 10^{-1}$ \\
\cline { 2 - 5 } & GDP per head & $1.60 \cdot 10^{-3}$ & $8.02 \cdot 10^{-4}$ & $5.79 \cdot 10^{-1}$ \\
\cline { 2 - 5 } & Total export-import volume & $5.73 \cdot 10^{-2}$ & $1.64 \cdot 10^{-1}$ & 9.19 \\
\cline { 2 - 5 } & Sigma-squared & $3.31 \cdot 10^{2}$ & $2.06 \cdot 10^{2}$ & $7.46 \cdot 10^{6}$ \\
\cline { 2 - 5 } & Gamma & 1.00 & 1.00 & 1.00 \\
\hline
\end{tabular}

Notes: S - Shanghai Port; B - Busan Port. 
Table 4. Results of the third stage

\begin{tabular}{|c|c|c|c|c|c|}
\hline Port & Year & crste & vrste & scale & Returns to scale \\
\hline \multirow{13}{*}{$S$} & 2005 & 1 & 1 & 1 & - \\
\hline & 2006 & 0.935 & 0.996 & 0.939 & irs \\
\hline & 2007 & 0.986 & 0.992 & 0.994 & irs \\
\hline & 2008 & 0.902 & 0.979 & 0.921 & irs \\
\hline & 2009 & 0.839 & 0.992 & 0.846 & irs \\
\hline & 2010 & 0.96 & 1 & 0.96 & irs \\
\hline & 2011 & 0.979 & 0.995 & 0.984 & irs \\
\hline & 2012 & 0.968 & 0.985 & 0.984 & irs \\
\hline & 2013 & 1 & 1 & 1 & - \\
\hline & 2014 & 1 & 1 & 1 & - \\
\hline & 2015 & 1 & 1 & 1 & - \\
\hline & 2016 & 1 & 1 & 1 & - \\
\hline & mean & 0.964 & 0.995 & 0.969 & - \\
\hline \multirow{13}{*}{ B } & 2005 & 1 & 1 & 1 & - \\
\hline & 2006 & 0.94 & 0.971 & 0.969 & irs \\
\hline & 2007 & 0.988 & 0.995 & 0.993 & irs \\
\hline & 2008 & 0.972 & 0.989 & 0.983 & irs \\
\hline & 2009 & 0.818 & 0.912 & 0.897 & irs \\
\hline & 2010 & 0.954 & 0.985 & 0.969 & irs \\
\hline & 2011 & 0.924 & 0.962 & 0.961 & irs \\
\hline & 2012 & 0.961 & 0.974 & 0.987 & irs \\
\hline & 2013 & 0.97 & 0.979 & 0.991 & irs \\
\hline & 2014 & 0.97 & 0.974 & 0.996 & irs \\
\hline & 2015 & 1 & 1 & 1 & - \\
\hline & 2016 & 0.994 & 1 & 0.994 & $d r s$ \\
\hline & mean & 0.958 & 0.978 & 0.978 & - \\
\hline
\end{tabular}

\section{Influence of ports on environment}

Influence of ports on environment mainly comes from three aspects, pollutant emissions from vessels, pollutant emissions from collection and distribution system and ecological pollution brought by port development. Shipping represented around $2.8 \%$ of the global $\mathrm{CO}_{2}$ emissions (IMO 2014) and are expected to increase by $50 \%$ in 2050 (UNCTAD 2016). According to the data of Shanghai Environmental Monitoring Center, in 2017, about 0.29 million tons of PM2.5, 23000 tons of sulphide and 22.93 million tons of carbon dioxide were discharged from ships in Shanghai. Sulphur dioxide, nitrogen oxides and PM2.5 produced by ships accounted for $12.4,11.6$ and $5.6 \%$ of the total discharge of the city, respectively.

The pollutant emissions caused by the collection and distribution system should also not be ignored. According to statistics, the energy consumption coefficient of road transportation is 23.1 times that of railways and 10 times that of waterways. While the collection and distribution of Shanghai Port and Busan Port are mainly completed by road. $80 \%$ of the container collection and distribution in Shanghai Port is completed by road, and less than $1 \%$ is completed by railway. And $88 \%$ of the container collection and distribution in Busan Port is completed by road. The continuous growth of Shanghai Port's throughput and the high proportion of highway collection and distribution will inevitably cause serious energy waste and air pollution.

On the other hand, due to the market economy and port decentralization of China, domestic ports have blindly invested in port construction to achieve performance growth and expand market share. In addition, it has resulted in overcapacity and excessive competition. Furthermore, the development and utilization of shoreline and land resources will inevitably have an impact on the environment, such as water pollution in the port area, destruction of marine ecological environment and dust pollution in the yard and dock. As a result, with the global environmental problems becoming more and more serious, it is urgent for ports to change their development strategy to achieve green and sustainable development.

\section{Sustainable recommendations}

Based on the results of the three-stage DEA, in order to realize sustainable development, suggestions on strengthening the management of pollutant emissions in Shanghai Port are as follows:

- ports' cooperation is necessary to control pollutant emissions from vessels. According to the report of the Natural Resources Conservation Commission of the United States, China has not yet promoted national efforts to curb shipping pollution, and only a few cities have begun to formulate plans to address this problem. Unless ports of China cooperate to implement control measures, shipping vessels will be transferred to ports with lax supervision. Pollution can only be transferred from one port to another, seriously weakening the overall effectiveness of clean ports. Furthermore, ports' cooperation in pollution control can obtain more total returns than independent pollution control (Wang et al. 2018);

- Shanghai Port should promote energy conservation and emission reduction technologies, also the lowcarbon and environmental protection technologies. It is also important to actively promote the work of shore-based power supply, and carry out technical transformation of "oil-to-electricity" or "oil-to-gas" for mechanical equipment. The lighting equipment of the station should use LED lights, and the berthing ships use shore-based power supply. Intelligent dispatch system should also be used to reduce equipment energy consumption.

Although the shipping industry has been slow to improve its environmental credentials, a combination of regulation and technological innovation provides it with significant potential to dramatically reduce its environmental impact, and that ports have a pivotal role to play in supporting this objective (Cullinane, K., Cullinane, S. 2019). 
As an important driving force for regional development, Shanghai Port should balance its own development with the environment. Improving port efficiency and achieving sustainable development through improving management level and promoting green strategy should be the focus of current work.

\section{Conclusions}

From the view of sustainable development and environmental protection, this study assesses the port efficiency of Shanghai Port and Busan Port, the two most competitive shipping centers in Northeast Asia, respectively by adopting the three-stage DEA. In addition, $\mathrm{NO}_{\mathrm{x}}$ emission is selected as an environmental variable in the second stage to examine the impact of ports' pollutant emissions on their respective input variables. The results reveal that both over scale and pollutant emissions are important factors resulting in insufficiency of Shanghai Port efficiency.

This paper aims to remind ports to make a balance between development and environmental protection. In addition, it is innovative in its use of the three-stage DEA to study the annual change in performance of a single target, and also the selection of environmental variables. This method can evaluate the effect of undesirable output on redundancy of input variables. In addition, it will contribute to China's ports as they can determine whether their green development strategy is in line with the requirements of sustainable development based on the results and timely adjust their development strategy.

Due to data availability and other reasons, this paper only considers $\mathrm{NO}_{\mathrm{x}}$ among many undesirable outputs when selecting environmental variables.

Further research is required to extend this scope, such as water pollution, noise, dust and so on.

\section{Funding}

This work was supported by the National Natural Science Foundation of China under Grant No 71371038, 71431001, 51879156; Shanghai Pujiang Program under Grant No 17PJC053.

\section{Author contributions}

Xiaoling Huang conceived the study.

Yawei Wang and Xiamei Dai were responsible for data collection and analysis.

Xiaoling Huang and Yawei Wang wrote the first draft of the paper.

Jack Xunjie Luo and Jihong Chen helped perform the analysis with constructive discussions.

\section{Disclosure statement}

All the authors have no conflict of competing financial, professional, or personal interests from other parties.

\section{References}

Aigner, D.; Lovell, C. A. K.; Schmidt, P. 1977. Formulation and estimation of stochastic frontier production function models, Journal of Econometrics 6(1): 21-37.

http://doi.org/10.1016/0304-4076(77)90052-5

Banker, R. D.; Charnes, A.; Cooper, W. W. 1984. Some models for estimating technical and scale inefficiencies in data envelopment analysis, Management Science 30(9): 1078-1092. http://doi.org/10.1287/mnsc.30.9.1078

Chang, Y.-T.; Park, H.; Lee, S.; Kim, E. 2018. Have emission control areas (ECAs) harmed port efficiency in Europe?, Transportation Research Part D: Transport and Environment 58: 39-53. https://doi.org/10.1016/j.trd.2017.10.018

Charnes, A.; Cooper, W. W.; Rhodes, E. 1978. Measuring the efficiency of decision making units, European Journal of Operational Research 2(6): 429-444. https://doi.org/10.1016/0377-2217(78)90138-8

Chen, C.; Lam, J. S. L. 2018. Sustainability and interactivity between cities and ports: a two-stage data envelopment analysis (DEA) approach, Maritime Policy \& Management: the Flagship Journal of International Shipping and Port Research 45(7): 944-961. https://doi.org/10.1080/03088839.2018.1450528

Chen, J.; Yahalom, S. 2013. Container slot co-allocation planning with joint fleet agreement in a round voyage for liner shipping, Journal of Navigation 66(4): 589-603. https://doi.org/10.1017/S0373463313000192

Cheon, S.; Maltz, A.; Dooley, K. 2017. The link between economic and environmental performance of the top 10 U.S. ports, Maritime Policy \& Management: the Flagship Journal of International Shipping and Port Research 44(2): 1-21. https://doi.org/10.1080/03088839.2016.1275860

Cullinane, K.; Cullinane, S. 2019. Policy on reducing shipping emissions: implications for "green ports", in R. Bergqvist, J. Monios (Eds.). Green Ports: Inland and Seaside Sustainable Transportation Strategies, 35-62.

https://doi.org/10.1016/B978-0-12-814054-3.00003-7

Dobos, I.; Vörösmarty, G. 2019. Inventory-related costs in green supplier selection problems with data envelopment analysis (DEA), International Journal of Production Economics 209: 347-380. https://doi.org/10.1016/j.ijpe.2018.03.022

IMO. 2014. Third IMO GHG Study 2014: Executive Summary and Final Report. International Maritime Organization (IMO), London, UK. 327 p. Available from Internet: http://www.imo. org/en/OurWork/Environment/PollutionPrevention/AirPollution/Documents/Third\%20Greenhouse\%20Gas\%20Study/ GHG3\%20Executive\%20Summary\%20and\%20Report.pdf

Lai, S.; Gao, J.; Yan, Y.; Wang, Y. 2012. The study of health resources allocation efficiency in Shaanxi province based on DEA method, Chinese Health Service Management 29(8): 572-574. http://doi.org/10.3969/j.issn.1004-4663.2012.08.003 (in Chinese).

Lee, T.; Yeo, G.-T.; Thai, V. V. 2014. Environmental efficiency analysis of port cities: Slacks-based measure data envelopment analysis approach, Transport Policy 33: 82-88.

https://doi.org/10.1016/j.tranpol.2014.02.009

Luo, J.; Cui, E.; Ji, J. 2014. An analysis on environmental efficiency of Chinese container ports with $\mathrm{CO}_{2}$ emissions based on SBM (Slacks Based Measurement) DEA, Science and Technology Management Research (21): 66-69. http://doi.org/10.3969/j.issn.1000-7695.2014.21.014 (in Chinese). 
Markovits-Somogyi, R.; Bokor, Z. 2014. Assessing the logistics efficiency of European countries by using the DEA-PC methodology, Transport 29(2): 137-145.

https://doi.org/10.3846/16484142.2014.928787

Meeusen, W.; Van den Broeck, J. 1977. Efficiency estimation from Cobb-Douglas production functions with composed error, International Economic Review 18(2): 435-444.

http://doi.org/10.2307/2525757

Merkel, A.; Holmgren, J. 2017. Dredging the depths of knowledge: efficiency analysis in the maritime port sector, Transport Policy 60: 63-74. https://doi.org/10.1016/j.tranpol.2017.08.010

Schøyen, H.; Bjorbæk, C. T.; Steger-Jensen, K.; Bouhmala, N.; Burki, U.; Jensen, T. E.; Berg, Ø. 2018. Measuring the contribution of logistics service delivery performance outcomes and deep-sea container liner connectivity on port efficiency, Research in Transportation Business \& Management 28: 66-76. https://doi.org/10.1016/j.rtbm.2018.03.002

Song, S. 2014. Ship emissions inventory, social cost and eco-efficiency in Shanghai Yangshan Port, Atmospheric Environment 82: 288-297. https://doi.org/10.1016/j.atmosenv.2013.10.006

Sun, J.; Yuan, Y.; Yang, R.; Ji, X.; Wu, J. 2017. Performance evaluation of Chinese port enterprises under significant environmental concerns: an extended DEA-based analysis, Transport Policy 60: 75-86. https://doi.org/10.1016/j.tranpol.2017.09.001

UNCTAD. 2016. Review of Maritime Transport 2016. United Nations Conference on Trade and Development (UNCTAD). 115 p. https://doi.org/10.18356/8a715c05-en

Wang, Q.; Zhao, L.; Zeng, L.; Zhang, Q. 2018. A game model of air pollution control from vessels in and around ports, in Proceedings of the 2018 4th International Conference on Humanities and Social Science Research (ICHSSR 2018), 25-27 April 2018, Wuxi, China. https://doi.org/10.2991/ichssr-18.2018.9

Wiegmans, B.; Witte, P. 2017. Efficiency of inland waterway container terminals: stochastic frontier and data envelopment analysis to analyze the capacity design- and throughput efficiency, Transportation Research Part A: Policy and Practice 106: 12-21. https://doi.org/10.1016/j.tra.2017.09.007

Yang, Z.; Guo, W. 2015. A study on the efficiency of health resource allocation in Beijing, Chinese Health Service Management 32(5): 359-363. (in Chinese).

Zhou, X.-J.; Jiang, G.-X. 2010. Evaluation and discussion on the allocative efficiency of health resource based on DEA, Modern Preventive Medicine (20): 3873-3875. (in Chinese). 